\title{
AS CONTRIBUIÇÕES DO DIALOGISMO DE BAKHTIN E DO SIGNO EM UMBERTO ECO PARA O ENSINO DE LÍNGUA ESTRANGEIRA
}

\author{
Sandra Regina SILVA ${ }^{1}$ \\ Antonio Francisco MAGNONI ${ }^{2}$
}

RESUMO: O presente artigo discute o dialogismo em Mikhail Bakhtin e a fundamentação do signo linguístico em Umberto Eco, com a intenção de utilizar os referidos temas e autores, para subsidiar as metodologias de ensino-aprendizado de língua estrangeira (inglês e espanhol) na rede de ensino público paulista. A abordagem conceitual dos dois autores nos permite inferir que o aprendizado de uma língua estrangeira é efetivado pela apropriação de enunciados e de conhecimento cultural, uma concepção pedagógica que confronta o método tradicional utilizado no ensino paulista, que é baseado, principalmente, no ensino de gramática e de léxicos. $\mathrm{O}$ artigo deriva da pesquisa teórica utilizada para subsidiar de uma dissertação de mestrado, que levanta e avalia preliminarmente, a integração das salas tradicionais de língua estrangeira nas escolas de ensino público, com ambientes digitais (em cursos on-line), e também os efeitos didático-pedagógicos da utilização de material audiovisual presencial e online.

PALAVRAS-CHAVE: Escola presencial-virtual. Inglês. Espanhol. EVESP.

\section{Introdução}

As aulas de língua inglesa ministradas nas escolas públicas estaduais de São Paulo ainda seguem formas tradicionais e se sustentam essencialmente no ensino de gramática e com as regras de conjugação dos tempos verbais, cujas lições são oferecidas em diversas listas de conjugações e que são complementadas pela utilização das novas cartilhas bimestrais de inglês para a introdução de métodos superficiais de leitura rápida (scanning) e de compreensão textual.

A nossa percepção inicial sobre a metodologia utilizada para o ensino de línguas estrangeiras é a de que as aulas tradicionais afastam os estudantes do ensino fundamental e do ensino médio da rede estadual pública paulista. Persiste nas escolas, a evidente falta de

\footnotetext{
1 Jornalista. UNESP - Universidade Estadual Paulista. Faculdade de Arquitetura, Artes e Comunicação. Mestranda do Programa de Pós-Graduação em TV Digital Informação e Conhecimento. UNESP Universidade Estadual Paulista. Faculdade de Arquitetura, Artes e Comunicação. Bauru - SP - Brasil. 17033-360 - sandra.silva@gmail.com.

${ }^{2}$ Doutor em Educação. UNESP - Universidade Estadual Paulista. Faculdade de Filosofia e Ciências. Pósdoutor. UNQ - Universidad Nacional de Quilmes. Docente do Programa de Pós-Graduação em TV Digital Informação e Conhecimento. UNESP - Universidade Estadual Paulista. Faculdade de Arquitetura, Artes e Comunicação. Bauru - SP - Brasil. 17033-360 - afmagnoni@ faac.unesp.br.
} 
motivação individual dos alunos, para o aprendizado verbal e escrito de uma segunda língua. Tais habilidades contribuiriam para que crianças e adolescentes tivessem acesso à informações culturais e aos novos conhecimentos, que são difundidos em inglês e espanhol, as duas línguas ocidentais mais utilizadas para publicação de informações na internet ou pelas programações das redes de TV por assinatura. As mensagens multimidiáticas, simultâneas e multilaterais, que transitam em tempo real pelas redes do ciberespaço, são disparadas de diversos dispositivos portáteis conectados em ambientes e ferramentas virtuais, como o Facebook, o Whatsapp, o Twitter e o Instagram. Conforme aumenta o volume de trocas de mensagens entre crianças, adolescentes e jovens, cuja maioria já é portadora de dispositivos individuais de telecomunicações, aparentemente ocorre um relativo resgate do uso de mensagens escritas. Há uma retomada coletiva do uso de signos, mensagens e enunciados verbais, sonoros e imagéticos, que são formas típicas de comunicação de sociedades cada vez mais regidas pelas linguagens sincréticas que transitam pelos aparatos digitais de comunicação e de interação cultural (CAPURRO, 2014).

A partir da vivência de docente em línguas estrangeira, avaliamos como complexo o desafio pedagógico para se obter bom rendimento no ensino de língua inglesa e espanhola, nas escolas públicas e estaduais de São Paulo. Afinal, a repetição de conteúdos escritos que é praticada diariamente nas salas de aula, parece que não tem servido para os estudantes do ensino fundamental e médio aprender de maneira satisfatória, as línguas estrangeiras obrigatórias no currículo brasileiro.

Diante de um desafio didático-pedagógico tão complexo, pensamos na apropriação do dialogismo de Bakhtin (2006) para substituir o método de repetição fonética de conteúdos, que é majoritariamente utilizado num processo de aprendizado para os estudantes do ensino fundamental e do ensino médio de línguas estrangeiras. A finalidade é da substituição é criar uma maneira natural e mais prazerosa de aprender uma nova língua. Também acreditamos que o ensino-aprendizado contemporâneo de língua estrangeira fundamentado no dialogismo, pode e deve ser complementado por novas tecnologias de comunicação, em especial por recursos audiovisuais interativos, que poderão oferecer aos estudantes, novas possibilidades de aproximação e de imersão cotidiana nas línguas que estão aprendendo. $\mathrm{O}$ uso de recursos didáticos que permitem comunicação e interação em tempo real está mais próximo das formas de comunicação das novas gerações e pode facilitar a apresentação das realidades culturais e sociais do universo linguístico estudado.

Também inferimos que o método dialógico de Bakhtin poderá ser um instrumento 
conceitual e didático-pedagógico eficaz para superar o baixo rendimento em línguas estrangeiras, da rede paulista de ensino público. A assimilação de uma nova língua exige do aprendiz, a incorporação cultural de signos que provocam a transformação social dos receptores, pela forma motivadora de transmissão de enunciados (BAKHTIN, 2006). O método do filólogo refuta com isso, as formas de ensino-aprendizado de línguas fundamentadas na rotina de repetição quase mecânica de palavras escritas na lousa e também no uso exaustivo e desmotivador de vocabulários herméticos, que são metodicamente transmitidos há muito tempo e da mesma forma, nas salas de aula.

A Secretaria de Educação do Estado de São Paulo (SEE) criou recentemente, cursos on-line de inglês e de espanhol na plataforma virtual Evesp (Escola Virtual de Programas Educacionais do Estado de São Paulo) para ensinar alunos do ensino médio de toda a rede pública estadual num modelo de escola presencial-virtual (EPV). No novo sistema, os alunos poderão fazer o curso on-line de inglês e espanhol em casa ou em outro ambiente virtual, num esforço de integração da educação escolar tradicional às práticas da Tecnologia da Informação e Comunicação (TIC), que permite os estudantes façam cursos optativos. O projeto começou a adotado desde 2012, apresenta resultados aparentemente incipientes e ainda sem dados avaliativos da Secretaria.

Paralelamente ao projeto online, a SEE implantou algumas unidades físicas dos Centros Especializado de Línguas (CEL) para o ensino-aprendizado de espanhol em aulas presenciais, que são destinadas para os alunos do ensino fundamental e do inglês para o ensino médio. Também, instalou polos experimentais do curso de inglês Early Bird (pássaro madrugador), em 50 escolas de ensino fundamental em escolas da rede pública estadual em 2014 em um projeto piloto para os primeiros anos do fundamental. Os cursos do CEL e do Early Bird são optativos e funcionam como disciplina complementar. O CEL utiliza material de áudio e vídeo enquanto o Early Bird tem foco na oralidade e a utilização de fantoches.

\section{Diretoria de Ensino (DE) de Bauru, local político-administrativo onde está alocado o projeto analisado.}

O objeto de nossa pesquisa será analisar em duas escolas vinculadas à Diretoria de Ensino (DE) de Bauru, as metodologias, os processos didático-pedagógicos e também averiguar se há resultados quantitativos e qualitativos sobre os cursos ministrados de língua estrangeira. Observaremos uma sequência de aulas presenciais e faremos a análise dos 
materiais didáticos utilizados, a partir dos referenciais teóricos da educação históricocrítica.

A DE regional de Bauru foi criada em 1976, com a junção das Delegacias de Ensino Básico e Normal (MAGNONI; SILVA, 2014, p.131) e gere os aspectos pedagógicos e administrativos das 82 unidades educacionais de Bauru e região. $\mathrm{O}$ curso experimental Early Bird ("pássaro madrugador") foi implantado em 2014 em Bauru, na E. E. Professora Marta Aparecida Hjertquist Barbosa, no bairro popular da Vila Nova Esperança. O curso presencial é fundamentado na oralidade e é disponibilizado para 781 alunos do ensino fundamental, com a utilização de material pedagógico (DVDs e cards), com uma média de 30 alunos por sala, o que põe à prova a eficácia do curso em um ambiente com muitos alunos.

Atualmente 16 municípios integram o perímetro político-administrativo da DE de Bauru que tem 82 unidades educacionais, com uma população escolar de 49.941 alunos, com idades médias entre 7 e 17 anos. No entanto, do universo de quase 50 mil alunos, menos de 1.000 alunos são atendidos anualmente pelos cursos presenciais de língua estrangeira ministrados no Centro Especializado de Línguas (CEL), e todos estão concentrados em Bauru, o que mostra uma evidente distorção na nova proposta de ensino de língua estrangeira da SEE. Pela proximidade geográfica decidimos pesquisar o Centro Especializado de Línguas (CEL) de Bauru, que está instalado na E. E. Christino Cabral, Jardim Estoril, um bairro de classe média da cidade, mas que atende um alunado mais pobre derivado dos núcleos residenciais populares concentrados num entorno entre 3 a 5 quilômetros da escola. O foco é o ensino-aprendizado de espanhol.

Para que seja entendido o estado da arte do Dialogismo para ensino de língua estrangeira, é necessário conhecer profundamente o conceito de "signo ideológico" (BAKHTIN, 2006), cujos sentidos ultrapassam a própria particularidade do signo em si, uma percepção bem diferente daqueles que defendiam na época de Bakhtin, a filosofia idealista e a visão psicológica de educação. Bakhtin, um filósofo da linguagem, com sua percepção científica de educação e de formação dos indivíduos, conceitua que tudo aquilo que é ideológico, possui significados que remetem para algo situado fora do próprio signo. Ao mesmo tempo, as referências ideológicas continuam conectadas aos outros signos, por meio de uma cadeia de criatividade e de compreensão ideológica, que constitui assim, a chamada cadeia ideológica.

O autor conceituou a natureza semiótica dos elos estabelecidos entre os signos e o entorno social e cultural, um processo intelectual indispensável para a compreensão de 
uma nova cultura, que deriva dos tantos vínculos humanos existentes em uma cadeia ideológica formada por uma profusão de consciências individuais, que são interligadas pelos espaços, percepções e práticas sociais coletivas.

Na perspectiva do pensamento de Bakhtin (2006), é possível afirmar que os signos linguísticos só afloram num processo de interação entre uma consciência e outra; eles são expressados a partir de uma determinada relação social entre os indivíduos. Apenas neste contexto a palavra é definida como um signo e como o indicador mais sensível das transformações sociais. Então, é possível concluir que só haverá aprendizado eficaz, se ocorrer interação dialógica entre quem ensina e quem aprende, e também entre todos os que aprendem um mesmo assunto em um mesmo espaço. A mera transmissão de palavras e de estruturas gramaticais que lembram mais um léxico de verbos ou um dicionário, não serve para ensinar de maneira libertadora, prazerosa e bem sucedida.

As palavras são tecidas a partir de uma multidão de fios ideológicos e servem de trama a todas as relações sociais em todos os domínios. É, portanto, claro que a palavra será sempre o indicador mais sensível de todas as transformações sociais, mesmo daquelas que apenas despontam e que ainda não tomaram forma, que ainda não abriram caminho para sistemas ideológicos estruturados e bem formados. (BAKHTIN, 2006, p. 32).

\section{A retórica da sedução}

Num processo de aprendizado de uma língua estrangeira, quando predomina apenas um discurso retórico e geralmente caracterizado pelo léxico incontestável e impositivo, para o aprendiz restará apenas se debater pelo êxito absoluto ou amargar o fracasso irremediável. Em um ou em outro caso, o estudante se tornou vítima da submissão cultural durante a ação de aprendizagem, o antimétodo que deriva das dificuldades não resolvidas nas tensas relações de ensino e de aprendizado.

Mesmo os sentidos passados, aqueles que nasceram do diálogo com os séculos passados, nunca estão estabilizados (encerrados, acabados de uma vez por todas). Sempre se modificarão (renovando-se) no desenrolar do diálogo subsequente, futuro. Em cada um dos pontos do diálogo que se desenrola, existe uma multiplicidade inumerável, ilimitada de sentidos esquecidos, porém, num determinado ponto, no desenrolar do diálogo, ao sabor de sua evolução, eles serão rememorados e renascerão numa forma renovada (num contexto novo). Não há nada morto de maneira absoluta. Todo sentido festejará um dia seu renascimento. O problema da grande temporalidade. (BAKHTIN, 1997, p.414) 
Para que compreendamos com mais profundidade a característica evolutiva da língua, acreditamos que haveria a necessidade de reconstruir o pensamento semiótico, desde a época clássica. Afinal, a semiótica contemporânea tornou-se uma ciência tomada pela angústia, diante das ciências humanas e sociais, que relutam em reconhecê-la como conhecimento que foi organizado a partir dos gregos estoicos, como verdadeiro discurso filosófico (ECO, 1991).

A partir dos conceitos básicos da semiótica do teórico - signo, símbolo (relações abstratas) e dos signos gráficos (desenhos, entre outros) - é possível investigar a amplitude dos processos de significação do signo para o ser humano dos signos que ele produziu desde as épocas mais remotas de sua evolução.

O signo (ou a função sígnica) apresenta-se, portanto, como a ponta emergente e reconhecível de uma rede de agregações e desagregações sempre aberta a uma outra combinação. O signo linguístico não é uma unidade do sistema de significação, mas uma unidade reconhecível do processo de comunicação. (ECO, 1991, p.26).

Na semiótica de Eco (1991), a chamada cadeia significante produz textos que trazem consigo a memória da intertextualidade em textos que geram a partir das diversas relações conceituais e perceptivas, variadas leituras e interpretações. Assim um texto é um aparato de comunicação que sempre questiona os conceitos de comunicação anteriores. Os questionamentos tanto poderão renová-las, quanto superá-las. Por exemplo, um texto escrito em língua estrangeira tem também a sua intertextualidade, num diálogo linguístico. Essa evolução do signo social sociolinguístico (ideológico) ocorre com as mudanças na forma do signo e que poderão ser definidas como o resultado direto das alterações que ocorrem nas condições sociais e na organização social das interações entre os indivíduos, relações cotidianas que também poderão alterar as formas linguísticas (BAKHTIN, 2006). Isso significa que o signo não é estático, está em constante movimento e transformação.

As línguas, maternas ou estrangeiras, são caracterizadas também por um processo criativo contínuo e que se materializa sob a forma de atos individuais da fala ou da escrita. Apenas a individualização estilística da língua em uma enunciação concreta histórica é realmente produtiva, e não a sua mera repetição. Isso porque, uma língua evolui com a expressão dos enunciados dos indivíduos e não apenas com a mera consciência de pensamentos difusos (BAKHTIN, 2006).

O pensador russo também aponta a constante tensão linguística como a fonte dos 
conflitos que ocorrem no aprendizado e na prática cotidiana de uma língua: enquanto a formalização gramatical tende a manter o estado anterior de uma língua, é a comunicabilidade diária que possibilita, por exemplo, a compreensão entre os falantes, num ato que reforça a identidade normativa da língua. É o elemento evolutivo do signo ideológico que vai criando novas possibilidades linguísticas. A evolução linguística passa então, a ser definida a partir de um padrão espontâneo seguido pelos falantes e que incorpora também os erros ou transgressões linguísticas, que vão configurando os ciclos evolutivos ou modificadores dos sistemas linguísticos.

Então, para identificarmos os processos de modificações linguísticas, precisamos observar como ocorre a conformação, os ajustes de uma língua ao universo cotidiano dos falantes? Diante de realidades tão diversas, as reconfigurações de uma língua à realidade dos falantes ocorrem em cada nova significação dada pelo locutor em um determinado contexto, para essa forma linguística. Neste processo, a forma linguística (o padrão da língua) pode ser definida como estável, enquanto o signo linguístico vai ser caracterizado pelas qualidades de flexibilidade e de variabilidade inseridas pelos falantes durante o uso cotidiano de uma língua. Assim, a apropriação de uma nova língua é também uma forma de interação dos enunciados direcionados a um destinatário, num processo de constante diálogo. O livro impresso, tal como ato de significado impresso, também é um elemento da comunicação verbal. Assim, o discurso escrito é de certa maneira, parte integrante de uma discussão ideológica em grande escala: ele responde a alguma coisa, refuta, confirma, antecipa as respostas e objeções potenciais, procura apoio etc. (BAKHTIN, 2006).

A significação das palavras é formada por elementos reiteráveis e idênticos na enunciação e o tema é um sistema único, dinâmico e complexo, de signos que procuram adaptar-se às condições de um determinado momento cotidiano. E neste contexto, a mudança na significação é sempre uma reavaliação e um deslocamento de uma palavra de um "contexto apreciativo" para outro. É a expressão, o enunciado, o instrumento linguístico que organiza a atividade mental das pessoas e não o contrário. Por isso, que durante o ensino-aprendizado de língua estrangeira é imperativo praticar exercícios constantes de diálogo e de escrita.

O filólogo compara os conflitos linguísticos com a luta de classes: para ele, as línguas convivem com constantes movimentos de pressão erudita, que defendem a conservação e a perpetuação das normas linguísticas, enquanto a interação social cotidiana dos indivíduos realiza muitos movimentos espontâneos e até involuntários, que contribuem para transformar e renovar as línguas. Enquanto a gramática e todas as normativas escritas 
das línguas realizam movimentos contínuos de conservação, os neologismos, gírias e estrangeirismos aceleram os processos renovadores das línguas.

Eco (1991), a partir de uma visão histórica da semiótica, também conceitua a função sígnica das línguas como instáveis e provisórias.

Não há interpretante que, ao conformar o signo que interpreta, não modifique, mesmo que só um pouco, seus limites. Interpretar um signo significa definir a porção de conteúdo veiculada em suas relações com as outras porções derivadas da segmentação global do conteúdo; e definir uma porção através do emprego de outras porções, veiculadas por outras expressões. Se a interpretação é levada muito adiante, há a possibilidade de pôr em crise não só o conteúdo detectado no começo, mas o próprio critério global de segmentação, o que significa por em questão a maneira de a forma do conteúdo segmentar o continuum. (ECO, 1991, p.59).

A matéria (continuum do qual os signos falam e através do que falam) é sempre a mesma. Mas o que motiva o signo como objeto dinâmico, é a interpretância exercida pelo sujeito, é a semiose (significação ou interpretação) e este sujeito é a pulsão que produz essa significação. Com isso, a consideração do autor é que a ciência dos signos é a ciência de como se constitui o sujeito ao longo da história num processo em que homem e palavra educam-se reciprocamente.

\section{As dificuldades dos aprendizes para identificar as palavras estrangeiras como signos}

A conceituação e a diferenciação da tomada de consciência do aprendiz durante o processo de aprendizado da língua materna e no processo de apropriação de uma língua estrangeira, onde a língua ainda não é reconhecida como língua, é um estágio consciente de não-identificação imediata da palavra como signo linguístico. Com isso, é possível concluir que muitas vezes a rejeição inicial dos alunos em tentar assimilar conteúdos em inglês, é na verdade uma falta de identificação com os próprios signos da língua inglesa.

A comunicação verbal na vida cotidiana não deixa de dispor de gêneros criativos. Esses gêneros do discurso nos são dados quase como nos é dada a língua materna, que dominamos com facilidade antes mesmo que lhe estudemos a gramática. A língua materna - a composição de seu léxico e sua estrutura gramatical -, não a aprendemos nos dicionários e nas gramáticas, nós a adquirimos mediante enunciados concretos que ouvimos e reproduzimos durante a comunicação verbal viva que se efetua com os indivíduos que nos rodeiam. Assimilamos as formas da língua somente nas formas assumidas pelo enunciado e juntamente com essas formas. As formas da língua e as formas típicas de enunciados, isto é, os gêneros do discurso, se introduzem em nossa experiência e em nossa consciência conjuntamente e sem que sua estreita correlação seja 
rompida. Aprender a falar é aprender a estruturar enunciados (porque falamos por enunciados e não por orações isoladas e, menos ainda, é óbvio, por palavras isoladas). (BAKHTIN, 1997, p.302).

Cada enunciado tem autor e destinatário, enquanto as unidades significantes da língua (palavras e orações) são de ordem impessoal e não pertencem a ninguém. Fala-se algo para alguém. Assim, também é o processo de aprender uma língua desconhecida, onde substitui-se os locutores indefinidos numa construção de enunciados possíveis numa relação de debate e de diálogo.

Para o pesquisador russo, ver uma coisa e tomar consciência dela pela primeira vez, é estabelecer uma relação de sentido entre enunciados na comunicação verbal, com uma compreensão responsiva. Compreender é ser o terceiro do diálogo porque pressupõe um super-destinatário superior, que poderá ser a religião, a história, as convicções e as experiências dos ouvintes, ou neste caso, a experiência de vivência do estudante. Por isso, a importância de se fundamentar também o ensino-aprendizado da língua estrangeira na experiência cultural do estudante, e não simplesmente no léxico.

\section{Considerações preliminares}

É possível considerar que os novos cursos de inglês e espanhol on-line da Evesp, oferecidos aos alunos do ensino fundamental e médio nas escolas públicas estaduais paulistas, também são uma tentativa dialógica de ensino-aprendizado com a utilização de recursos audiovisuais, num ambiente em que pela primeira vez e de forma mais livre, o estudante de língua estrangeira do ensino médio da escola pública estadual tem acesso à voz e à imagem do emissor do conteúdo num processo de ensino-aprendizado, apesar do ambiente virtual utilizado ter uma configuração extremamente empresarial, que se distancia bastante do cotidiano dos estudantes do ensino médio. Por exemplo, no curso online de espanhol da Evesp, o aluno tem a possibilidade de realizar um tour virtual pelos países de língua espanhola, em uma interação cultural em tempo real. E embora o curso seja realizado de forma autônoma e independente, o aluno tem a oportunidade de "dialogar" com o outro lado do conteúdo oferecido, sem se prender apenas na visão institucional da Secretaria de Educação sobre os países de língua hispânica.

No curso Early Bird, os alunos ingressantes no ensino fundamental da rede pública estadual experimentam pela primeira vez a prática do dialogismo, por meio da utilização 
de fantoches e vídeos em sala de aula. Assim, o ensino-aprendizado não fica condicionado apenas ao léxico. A conversa inicial que fizemos com a diretoria da unidade escolar E. E. Professora Marta Aparecida Hjertquist, no bairro Vila Esperança, em Bauru, sinalizou que o projeto tem intenção de estabelecer uma relativa interação com a comunidade atendida. Em 2014, os estudantes do ensino fundamental já fizeram a apresentação de músicas cantadas em inglês em evento na escola, com a presença dos pais e da comunidade do entorno.

Em relação ao curso de espanhol do Centro Especializado de Língua (CEL), em uma primeira visita ao CEL localizado ao E. E. Christino Cabral verificamos a existência de signos de identificação com a Argentina e países latinos (nota-se bandeira do país vizinho no pátio, na parede recoberta de signos e desenhos que remetem ao universo da língua espanhola) e os estudantes são descritos pela coordenação com o adjetivo "estimulados" nas aulas e que interagem verbalmente durante as aulas sem necessariamente ocuparem uma posição de liderança. Nas aulas os alunos também interagem com outras mídias, assistindo conteúdos em espanhol.

As tentativas brasileiras de se utilizar os meios de comunicação para fins educativos, praticamente começaram com a criação da Rádio Sociedade do Rio de Janeiro, em 1923, por Edgard Roquette Pinto que, em 1928, criou um curso a distância em parceria com os escolanovistas da rede educacional do Distrito Federal, com material enviado pelos Correios e aulas pelo rádio. Mas a iniciativa teve um alcance restrito porque naquela época, o rádio era um veículo pouco acessível. No governo de Vargas as iniciativas de comunicação com fins educativos passaram a ser mais instrumentos de propaganda política do que propriamente de expansão do conhecimento (MAGNONI, 2001, p.149).

A produção de conteúdo educativo transmitido para rádios de todo o país, acabaram motivando iniciativas de longo prazo, como o projeto Minerva durante o Regime Militar, que criou a Radiobrás em 1975, estrutura educativa que foi agregada pela Empresa Brasileira de Comunicação (EBC). Mas no final dos anos 1980, já num período democrático, houve o início da privatização e o desmonte da estrutura de comunicação pública do país.

Portanto, é necessário ressaltar que as recentes iniciativas de hibridização da escola com a utilização das TICs, ainda abrangem uma parte ínfima dos estudantes da rede pública estadual paulista. Os cursos deveriam ser universalizados em toda a rede de escolas do Estado, para que efetivasse o ensino-aprendizado de língua estrangeira. As TICs não são apenas ferramentas necessárias para as aulas dos cursos virtuais de língua estrangeiras. 
Elas são essenciais para o novo modelo de EPV (escola virtual-presencial), que pode abranger um grupo de estudantes num entorno virtual ou em uma sala de aula física ou ainda, conectados individualmente em casa, transformada em home-school. Essa investigação também pondera que os ambientes de EPV, muitas vezes são concebidos apenas como ferramentas de inovação burocrática ou para servir a um apelo mercadológico das instituições, e não como instrumentos efetivos de inovação e de universalização educacional (MAGNONI; MAGNONI, 2012). Para que tal perspectiva se torne efetiva, é preciso investir também na democratização das TICs na escola, integrando o modelo de curso virtual ao presencial e fortalecer a presença do professor como orientador do processo de ensino-aprendizagem e como sujeito mediador dos meios e dos processos que sirvam para fazer avançar os conhecimentos e o desempenho escolar de todos os alunos da rede pública estadual de ensino.

\title{
THE CONTRIBUTIONS OF THE DIALOGISM IN BAKHTIN AND SIGN ON UMBERTO ECO FOR THE TEACHING OF FOREIGN LANGUAGE
}

\begin{abstract}
This article discusses the dialogism in Mikhail Bakhtin and the grounds of the linguistic sign in Umberto Eco, with the intention to use the themes and authors, to support the teaching-learning methodologies of foreign language (English and Spanish) at the public school of São Paulo state. The conceptual approach of the two authors allows us to infer that learning a foreign language is effected by the appropriation of utterances and cultural knowledge, pedagogical concept that confronts the traditional method used in the São Paulo school, which is based mainly on grammar teaching and lexicons. The paper derives the theoretical research used to support a dissertation, posing and evaluates preliminary, the integration of traditional theaters in foreign language in public schools, with digital environments (in online courses), and also the educational effects -the use of audiovisual material at the classroom and online learning.
\end{abstract}

KEYWORDS: Face-virtual school. English. Spanish. EVESP

\section{REFERÊNCIAS}

BAKHTIN, M. Estética da criação verbal. 2.ed. São Paulo: Martins Fontes, 1997.

Marxismo e filosofia da linguagem. 12.ed. São Paulo: Hucitec, 2006.

CAPURRO, R. Rafael Capurro concede entrevista ao Blog Dissertação sobre

divulgação científica. [7 out. 2014]. Entrevistador: Blog Dissertação sobre divulgação científica. Disponível em: <http://dissertacaosobredc.blogspot.com.br/2014/10/rafaelcapurro-concede-entrevista-ao.html>. Acesso em: 4 nov. 2014. 
ECO, U. Semiótica e filosofia da linguagem. São Paulo: Ática, 1991.

MAGNONI, A. F. Primeiras aproximações sobre pedagogia dos multimeios para o ensino superior. Marília: Ed. da UNESP, 2001.

.; MAGNONI, M. G. M. A educação para os "meios e os fins": a informação, o conhecimento e a comunicação na educação escolar básica e universitária. Bauru: Ciência Geográfica, 2012.

.; SILVA, S. R. O desafio da interação no ensino de língua estrangeira em cursos on-line e presenciais nas escolas públicas paulistas Revista Educação e Linguagens, Campo Mourão, v.3, n.5, p.128-144, jul./dez. 2014. 